\title{
The study of postural workload in assembly of furniture upholstery
}

\author{
Andrzej Marek Lasota ${ }^{1, *}$ and Krzysztof Hankiewicz ${ }^{2}$ \\ ${ }^{1}$ University of Zielona Gora, Institute of Safety Engineering \& Work Science, Prof. Z.Szafrana 4 \\ Street, 65-516 Zielona Gora, Poland \\ ${ }^{2}$ Poznan University of Technology, Chair of Management and Computing Systems, 11 Strzelecka \\ Street, 61-845 Poznan, Poland
}

\begin{abstract}
The productivity of the workers is affected by the Work-related Musculoskeletal Disorders (WRMSDs) which common cause of health problems, sick leave and it can result in decreased quality of work and increased absenteeism. The objective of this study is to evaluate and investigate the postural workload of sewing machine operators in the assembly of upholstery in furniture factory by using the Ovako Working Posture Analysing System (OWAS) with sampling. The results indicated that posture code 2111 (back code: 2 - bent forward; arms code: 1 - both below the shoulder joint; legs code: 1 - sitting position; load code: -1 less than $10 \mathrm{~kg}$ ) was the most common working posture rating $38.1 \% ; 63.9 \%$ of positions displayed non-neutral back postures and $52 \%$ received harmful action categories. The performed assembly tasks have an influence on harmless and harmful action categories. This study is crucial on assembly, and in the future work allows develop a framework for assessment the physical risk of WRMSDs in assembly.
\end{abstract}

\section{Introduction}

The ergonomics and environment factors have been the core issue for industry for many years and its profiles are rising. To ensure an ergonomics work environment, it is possible to require specific attention in carry out industry processes [1]. The needs that are the basis of the ability to work in a particular environment are dealt with in terms of working conditions [2]. The productivity of the workers is affected by the Work-related Musculoskeletal Disorders (WRMSDs) which common cause of health problems, sick leave and it can result in decreased quality of work and increased absenteeism in many professions. For example, in the United States, in 2015 musculoskeletal disorders accounted for $32 \%$ of all absence from work due to sickness [3]. In the Great Britain, in $2015 / 2016$ WRMSDs accounted $41 \%$ of all work related illnesses and it is estimated 8.8 million working days were lost due to WRMSDs what represent $34 \%$ of all days lost due to work related ill health [4].

\footnotetext{
*Corresponding author: am.lasota@,02.p1
} 
In Poland, in 2015 they cause over 33 million days of absence, accounting for $14.7 \%$ of all absences [5]. Thus, WRMSDs are a serious problem in many industry sectors $[6,7]$. The main ergonomic risk factors for WRMSDs are: awkward posture, repetition, excessive physical load, forceful exertion, and duration of movement [8, 9]. Moreover, arrangement of workstations, tasks and working methods, tools and anthropometric characteristics of workers have an influence on working postures [10]. The other problem is the adaptation of work stands to the elderly. Tools should be designed according to their capabilities [11]. Additionally general fatigue during the work should be analyze in complex way and it is possible to develop fatigue management system [12].

Sewing machine operators usually perform piecework jobs and assemble parts of components to create a final product. Their job requires precision, is highly repetitive, and usually involves both upper limbs, is visually demanding and requires a high degree of concentration $[13,14]$. Studies have shown the occurrence of WRMSDs in sewing machine operators in the textile and garment manufacturing industries [13, 15]. According to the authors' knowledge, there are not studies focused on sewing assembly process and furniture industry. Therefore the objective of this study was to evaluate and investigate the postural workload of sewing machine operators in the assembly of upholstery in a furniture factory.

\section{Methodology}

The case study was conducted in the upholstery sewing department of a furniture factory in Poland. The factory produces upholstered furniture (e.g. armchairs, sofas, etc.). The sample consisted of five women sewing machine operators aged from 29 to 51 years. Employees were informed about the study and participated in it as volunteers. The whole assembly process is divided into 5 tasks: sewing seats, sides, backs, on decorations and all parts together. Operators checked the dimensions of the fabric cut out with the dimensions in the project and began sewing. At the decoration sewing position, the employee first sewed them manually and then sewed them again on the machine. Assembly of all parts together began with checking of the correctness of parts sewn on the previous positions.

To collect data have been used: "pen and paper" observation, face-to-face interviews, task analysis and posture evaluation. Observations of the tasks performed by employees were preceded by face-to-face interview with supervisors and employees. The evaluations were recorded directly onto the prepared evaluation worksheet. Postures were selected with time sampling ( $30 \mathrm{~s}$ interval). This time interval allowed working postures to be assessed freely and a high density of samples to be recorded. In the entire assembly process 355 work postures adopted by the operators were evaluated; 71 postures for each of five tasks.

For the evaluation the OWAS method [16] was applied; it is one of the simpler observation techniques and allows a quick assessment. This method is based on a classification of different positions for the back, arms, legs and the force/load used in the work. The OWAS method uses a four-digit code to describe various postures and force/load combinations. The codes include four back postures (1-straight, 2 - bent forward, 3 - twisted, 4 - bent and twisted); three arm postures (1 - both below the shoulder joint, 2 - one above the shoulder joint, 3 - both above the shoulder joint), seven leg postures (1 - sitting position, 2 - standing with straight legs, 3 - standing with one leg extended, 4 - standing with legs bent, 5 - standing with one leg bent, 6 - kneeling on one or both knees, 7 - walking); and three variants of load (1 - less than $10 \mathrm{~kg}, 2$ - from 10 to $20 \mathrm{~kg}$, 3 - over $20 \mathrm{~kg}$ ). These four-digit codes from different body parts in a specific position combined with the estimated load provide information about each postural load. For example, 1241 indicates that the worker's back is straight (back code: 1), working with one arm above the shoulder joint (arms code: 2), standing with legs bent (legs code: 4), and handling a load weighing less than $10 \mathrm{~kg}$ (load code: 1 ). The combination creates categories 
describing the risk of exposure to WRMSDs and action categories (AC) necessary to improve the working conditions: AC1 - No risk: normal posture, with no particular adverse effect on the musculoskeletal system. Intervention is not required; AC2 - Low risk: working posture has a slight detrimental effect on the musculoskeletal system, there is a light load, immediate intervention is not required, but the ergonomic adjustment should be taken into account in future actions; AC3 - Medium risk: working posture has a significant detrimental effect on the musculoskeletal system; ergonomic intervention should be carried out as soon as possible; AC4 - High risk: working posture has a very high detrimental effect on the musculoskeletal system; ergonomic intervention is required immediately [17].

The Pearson's Chi-squared test was used to assess differences in harmless postures (AC1) with harmful postures (AC2, AC3, AC4). The Wilcoxon signed-rank test was conducted for comparing the AC results of evaluated tasks. Statistically significant differences were accepted at the $5 \%$ level of probability $(\mathrm{p}<0.05)$.

\section{Results}

The frequency of posture codes in the following tasks: sewing seats, sewing sides, sewing backs, sewing on decorations, sewing all parts together and complete assembly of all parts in the final product were various (Table 1).

Table 1. Frequency (\%) of posture code in tasks and entire process.

\begin{tabular}{|c|c|c|c|c|c|c|c|}
\hline Posture code & Seats & Sides & Backs & Decorations & All parts & Total & Action Categories \\
\hline 1111 & 42.3 & 25.4 & 22.5 & 50.7 & 9.9 & 30.1 & AC1 \\
\hline 1121 & - & 1.4 & - & - & - & 0.3 & AC1 \\
\hline 1131 & - & - & 2.8 & - & - & 0.6 & AC1 \\
\hline 1211 & - & - & - & 4.2 & - & 0.8 & AC1 \\
\hline 1221 & - & 5.6 & - & - & - & 1.1 & AC1 \\
\hline 1311 & - & - & 4.2 & - & - & 0.8 & AC1 \\
\hline 1331 & - & - & 5.6 & - & - & 1.1 & AC1 \\
\hline 2111 & 45.0 & 35.3 & 26.9 & 36.6 & 46.4 & 38.1 & AC2 \\
\hline 2121 & - & 4.2 & - & - & - & 0.8 & AC2 \\
\hline 2131 & - & - & 8.5 & - & - & 1.7 & AC2 \\
\hline 2221 & - & 1.4 & - & - & - & 0.3 & AC2 \\
\hline 2311 & - & - & 4.2 & - & - & 0.8 & AC3 \\
\hline 2321 & - & 9.9 & 4.2 & - & - & 2.8 & AC2 \\
\hline 2331 & - & - & 5.6 & - & 11.3 & 3.4 & AC3 \\
\hline 3111 & 12.7 & 5.6 & 5.6 & 8.5 & - & 6.5 & AC1 \\
\hline 3121 & - & - & - & - & 1.4 & 0.3 & AC1 \\
\hline 3151 & - & - & 9.9 & - & - & 2.0 & AC4 \\
\hline 3221 & - & - & - & - & 9.9 & 2.0 & AC1 \\
\hline 3321 & - & - & - & - & 21.1 & 4.2 & AC1 \\
\hline 4111 & - & 7.0 & - & - & - & 1.4 & AC2 \\
\hline 4211 & - & 1.4 & - & - & - & 0.3 & AC3 \\
\hline 4221 & - & 2.8 & - & - & - & 0.6 & AC2 \\
\hline Total & 100 & 100 & 100 & 100 & 100 & 100 & \\
\hline
\end{tabular}

In total, for the sewing process the most common posture code was 2111 ( 2 - back bent forward, 1 - arms both below the shoulder joint, 1 - legs, sitting position, 1 - load less than $10 \mathrm{~kg}$ ) and amounted to $38.1 \%$; whereas second most common was posture code: 1111 (30.1\%). A total of $47.8 \%$ of postures classified as $\mathrm{AC} 1,45.7 \%$ as $\mathrm{AC} 2, \mathrm{AC} 3-4.5 \%$ and AC4 $-2.0 \%$. At the seat sewing position, the most frequent results were: posture code $2111(45.0 \%)$, followed by posture code $1111(42.3 \%)$ and $3111(12.7 \%)$. A total of $55.0 \%$ 
of postures were classified into $\mathrm{AC} 1$ and for $\mathrm{AC} 2-45 \%$. For sewing sides 11 various postures were observed. The most common postures were: $2111(35.3 \%), 1111(25.4 \%)$ and 2321 (9.9\%); the resulting action categories were AC1 - 38.0\%, AC2 - 60.6\%, AC3 $1.4 \%$. At the back sewing position 11 various postures were observed; the most common were: 2111 (26.9\%), $1111(22.5 \%)$ and 3151 (9.9\%). There were: AC1 - 40.8\%, AC2 $39.4 \%$, AC3 $-9.9 \%$, AC4 $-9.9 \%$. At the position of sewing on decorations 4 different postures were recorded. The most common postures were: $1111(50.7 \%), 2111(36.6 \%)$. In terms of action categories, at $\mathrm{AC} 1$ were $63.4 \%$ of cases and at $\mathrm{AC} 2-36.6 \%$. Finally, at the last task - sewing all parts together -6 different postures were observed and the most common were: $2111(46.4 \%), 3321$ (21.1\%), 2331 (11.3) and 1111 (9.9\%). At AC1 were $42.3 \%$ cases, AC2 - 46.4\%, AC3 - 11.3\%.

Table 2. Proportion of OWAS working postures (\%) during performed tasks.

\begin{tabular}{|c|c|c|c|c|c|c|c|}
\hline \multicolumn{2}{|c|}{ Body parts } & Seats & Sides & Backs & Decorations & All parts & Total \\
\hline 1 & straight & 42.3 & 32.4 & 40.8 & 54.9 & 9.9 & 36.0 \\
\hline 2 & bent forward & 45.1 & 49.3 & 49.3 & 36.6 & 57.7 & 47.6 \\
\hline ص 3 & twisted & 12.6 & 5.6 & 9.9 & 8.5 & 11.3 & 9.6 \\
\hline 4 & bent and twisted & 0.0 & 12.7 & 0.0 & 0.0 & 21.1 & 6.8 \\
\hline 1 & both below the shoulder joint & 100.0 & 80.3 & 76.1 & 95.8 & 57.7 & 82.0 \\
\hline E] 2 & one above the shoulder joint & 0.0 & 11.3 & 0.0 & 4.2 & 9.9 & 5.1 \\
\hline$\ll 3$ & both above the shoulder joint & 0.0 & 8.5 & 23.9 & 0.0 & 32.4 & 12.9 \\
\hline 1 & sitting position & 100.0 & 76.1 & 63.4 & 100.0 & 56.3 & 79.1 \\
\hline 2 & standing with straight legs & 0.0 & 23.9 & 4.2 & 0.0 & 32.4 & 12.1 \\
\hline 3 & standing with one leg extended & 0.0 & 0.0 & 22.5 & 0.0 & 11.3 & 6.8 \\
\hline 4 & standing with legs bent & 0.0 & 0.0 & 0.0 & 0.0 & 0.0 & 0.0 \\
\hline 5 & standing with one leg bent & 0.0 & 0.0 & 9.9 & 0.0 & 0.0 & 2.0 \\
\hline 6 & kneeling on one or both knees & 0.0 & 0.0 & 0.0 & 0.0 & 0.0 & 0.0 \\
\hline 7 & walking & 0.0 & 0.0 & 0.0 & 0.0 & 0.0 & 0.0 \\
\hline 1 & $<10 \mathrm{~kg}$ & 100.0 & 100.0 & 100.0 & 100.0 & 100.0 & 100.0 \\
\hline ๘ 2 & $10-20 \mathrm{~kg}$ & 0.0 & 0.0 & 0.0 & 0.0 & 0.0 & 0.0 \\
\hline$\sqrt[3]{3}$ & $>20 \mathrm{~kg}$ & 0.0 & 0.0 & 0.0 & 0.0 & 0.0 & 0.0 \\
\hline
\end{tabular}

The proportion of OWAS work postures (\%) during performed tasks (Table 2) shows that in total for this assembly process, the back in $36.0 \%$ of cases was straight, $47.6 \%-$ bent forward, $9.6 \%$ - twisted and $6.8 \%$ - bent and twisted. Arms were in $82.0 \%$ of tasks both below the shoulder joint, $5.1 \%$ - one above the shoulder joint and $12.9 \%$ - both above the shoulder joint. Results for the legs were: $79.1 \%$ - sitting position, $12.1 \%$ - standing with straight legs, $6.8 \%$ - standing with one leg extended and only $2.0 \%$ - standing with one leg bent. Load in all cases was less than $10 \mathrm{~kg}$.

Table 3. Harmless (AC1) vs. harmful (AC2, AC3, AC4) action categories (\%), Pearson's chi-square test, $\mathrm{df}(4)$.

\begin{tabular}{|c|c|c|c|c|}
\hline Tasks & Harmless & Harmful & $\mathbf{X}^{2}$ & $p$ \\
\hline Seats & 55 & 45 & \multirow{5}{*}{18.39} & \multirow{5}{*}{0.001} \\
\hline Sides & 38 & 62 & & \\
\hline Backs & 41 & 59 & & \\
\hline Decorations & 63 & 37 & & \\
\hline All parts & 42 & 58 & & \\
\hline Total & 48 & 52 & - & - \\
\hline
\end{tabular}

The results show differences in \% of harmless (AC1) and harmful (AC2, AC3, AC4) action categories for each task and for the whole assembly process (Table 3 ). In total it was noticed more harmful action categories (52\%) than harmless $(48 \%)$ and it was observed a 
strong association between the tasks and the harmless and harmful action categories $\left(\mathrm{X}^{2}=18.39, \mathrm{p}<0.001\right)$. The Wilcoxon signed rank test shows statistically significant differences of AC between tasks performed by operators: "All parts" vs. "Decoration" $(p<0.005)$, "All parts" vs. "Seats" $(p<0.05)$, "Backs" vs. "Decoration" $(p<0.001)$, "Backs" vs. "Seats" $(p<0.01)$, "Decoration" vs. "Sides" $(p<0.001)$ and "Seats" vs. "Sides" $(p<0.05)$.

\section{Discussion}

This case study identified that the most common work posture for the overall process of assembly was 2111 . Additionally the bent forward trunk was the most critical back posture that should be eliminated or reduced for sewing machine operators. It was only in the case of sewing on decorations that the most common posture was 1111 - neutral. These differences are caused by the fact that the decoration worker performs the task in two phases. In the first phase she sews them by hand and in the second stage attaches them by sewing on a machine. In three tasks out of five it was noted the most strenuous poor work postures (AC3, AC4). For the sewing of sides, only one posture was coded at $4211(1.4 \%$, AC3), which was observed when workers were reaching for scissors. At sewing of the backs, 3 postures were coded 2311 (4.2\%, AC3), which was noticed during the exchange and reloading of spools of thread. Four postures were recorded as 2331 (5.6\%, AC3) - in standing position, when worker rotating element and visual inspection; and 7 postures $3151(9.9 \%$, AC4) during placement in the container. At the final assembly stage: 2331 $(11.3 \%, \mathrm{AC} 3)$ - while rotating the entire element and conducting visual inspection. Over the entire assembly process only $6.5 \%$ of tasks at AC3 \& AC4 are noticed.

The next authors' findings indicate that the proportion of back posture shows wide variation among tasks. However, the dominant postures are: bent forward and straight. The most common arm posture is both below the shoulder joint. However, in the task of sewing all parts together it was observed that approximately $1 / 3$ arms postures were both above the shoulder joint. This can be explained in that the joining by sewing of all parts together and visual control of sewed parts requires manual handling, rotating of parts sometimes taking place in a standing position because of their large size.

The greater proportion of legs shows that the process was made in the sitting position but at certain workplaces: sewing sides, backs and assembly of all parts some operations required a standing position (e.g. rotating, placement, visual inspection of parts).

The next authors' discovery shows a strong association between performed tasks and the harmless and harmful action categories $(\mathrm{p}<0.001)$. In this process of sewing it was observed more harmful AC (52\%) than harmless $(48 \%)$ postures. Moreover, the results indicates statistical significant differences in medians of action categories between "All parts" vs. "Decoration", "All parts vs. Seats", "Backs" vs. "Decoration", "Backs" vs. "Seats", "Decoration" vs. "Sides" and "Seats" vs. "Sides". This means that there are differences in harmful postures. This knowledge should help in the development of a job rotation schedule.

In this study the observations covered the whole assembly process. This approach has some advantages. Firstly, it makes it possible to identify the tasks that involve a high risk of exposure to poor postures. Secondly, this approach can recognize postures with a distinctly or extremely harmful effect on the musculoskeletal system for the identified tasks. Thirdly, this approach can recognize weaknesses in relation to postures in the process of assembly. Finally, this knowledge allows the management and control of risk on performed tasks in assembly before they develop into serious musculoskeletal disorders and allows the development of a job rotation schedule. There are, however, also some limitations to this study. Postures were evaluated at 30 seconds intervals and some postures occurring within the sampling period could have been missed. 71 samples are not cover enough of all possible postures at the task do not allow a full picture of working postures to be obtained. 


\section{Conclusions}

The results of this study indicate a negligible workload that requires soon or immediate ergonomic intervention, however, a deeper analysis indicates excessive back workload that may lead to WRMSDs. The knowledge from this study should be used to identify and control risks associated with the performed tasks and to develop a job rotation system, eliminating adverse exposure before it is able to develop into serious musculoskeletal disorders. This study is crucial on assembly, and in the future work allows develop a framework for assessment the physical risk of WRMSDs in assembly.

Based on the results of this study the following are recommended:

- Rearrangement of equipment,

- Develop and implement a job rotation schedule,

- Develop training on correct working practices (e.g. posture during operation, proper usage of tools and workstations), rest.

\section{References}

1. A. Górny, MATEC Web of Conferences, 94, 04011 (2017)

2. A. Górny, Procedia Manufacturing, 3, 4700 (2015)

3. Bureau of Labor Statistics 2016, Nonfatal Occupational Injuries and Illnesses Requiring Days Away from Work, http://www.bls.gov/news.release/pdf/osh2.pdf (2015)

4. HSE, Health and Safety Executive, Work Related Musculoskeletal Disorder Statistics (WRMSDs) in Great Britain 2016, Available from: http://www.hse.gov.uk/Statistics/causdis/musculoskeletal/msd.pdf?pdf=msd (2016)

5. ZUS, Absencja chorobowa w 2015 roku. ZUS, Warszawa, Available from: http://www.zus.pl/documents/10182/39590/Absencja+chorobowa+w+2015+roku.pdf/c 36a1432-adcf-4f6f-8d72-5d1108e7ab8a?version=1.0 (in Polish) (2016)

6. A. M. Lasota, K. Hankiewicz, Evaluation of ergonomic risk in the production line of frozen food products, Yue, X.G., Duarte, N.J.R. (Eds.), International Conference on Economics and Management Innovations - CEMI, ACSR-Advances in Computer Science Research. Atlantis Press, Paris, France, 272 (2016)

7. J. M. Lu, L. J. Twu, M. J. J. Wang, Int J Ind Ergonom, 52, 40 (2016)

8. A. M. Lasota, K. Hankiewicz, Assessment of risk to work-related musculoskeletal disorders of upper limbs at welding stations, Arezes, P.M., Baptista, J.S., Barroso, M.P. Carneiro, P., Cordeiro,P., Costa, N., Melo, R.B., Miguel, A.S., Perestrelo, G. (Eds.), International Symposium on Occupational Safety and Hygiene - SHO 2016; proceedings book. Guimaraes, Portugal, 138 (2016)

9. P. Coenen, M. Douwes, S. van den Heuvel, T. Bosch, Ergonomics, 59 (9), 1182 (2016)

10. E. R. Vieira, S. Kumar, J Occup Rehabil, 14 (2), 143 (2004)

11. M. Butlewski, Applied Mechanics and Materials 657, 1061 (2014)

12. M. Butlewski, G. Dahlke, M. Drzewiecka, L. Pacholski, Procedia Manufacturing, 3, $4732(2015)$

13. N. J. Delleman, J. Dul, Int J Ind Ergonom, 30 (6), 341 (2002)

14. N. Öztürk, M.N. Esin, Int J Ind Ergonom, 41 (6), 585 (2011)

15. I. Dianat, M. Kord, P. Yahyazade, M. Karimi, A. Stedmon, Appl Ergon, 51, 180 (2015)

16. O. Karhu, P. Kansi, I. Kuorinka, Appl Ergon, 8 (4), 199 (1977)

17. A. M. Lasota, K. Hankiewicz, Working Postures of Spot Welding Machine Operators, Arezes PM. et al. (Eds.), Occupational safety and hygiene IV, Taylor \& Francis Group, London, 261 (2016) 